The digital Dalton Plan: Progressive education as integral part of web-based learning environments

\author{
Georg Weichhart \\ Christian Stary \\ Johannes Kepler University Linz, Austria \\ Markus Appel \\ University of Würzburg, Germany
}

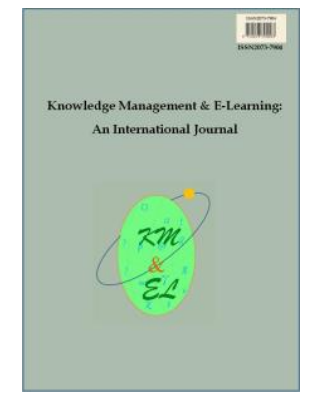

Knowledge Management \& E-Learning: An International Journal (KM\&EL) ISSN 2073-7904

Recommended citation:

Weichhart, G., Stary, C., \& Appel, M. (2018). The digital Dalton Plan:

Progressive education as integral part of web-based learning environments.

Knowledge Management \& E-Learning, 10(1), 25-52. 


\title{
The digital Dalton Plan: Progressive education as integral part of web-based learning environments
}

\section{Georg Weichhart*}

Flexible Production Systems, PROFACTOR GmbH, Gleink-Steyr, Austria Department of Business Information Systems - Communications Engineering Johannes Kepler University Linz, Austria

E-mail: georg.weichhart@ profactor.at

\section{Christian Stary}

Department of Business Information Systems - Communications Engineering Johannes Kepler University Linz, Austria

E-mail: christian.stary@jku.at

\section{Markus Appel}

Faculty of Human Sciences - Media Communication

University of Würzburg, Germany

E-mail: markus.appel@uni-wuerzburg.de

*Corresponding author

\begin{abstract}
Learning systems increasingly support learning management and self-organized learning processes. Since the latter have been studied in the field of progressive education extensively, it is worthwhile to consider them for developing digital learning environments to support self-regulated learning processes. In this paper we aim at transforming one of the most prominent and sustainable approaches to self-organized learning, the "Dalton Plan" as proposed by Helen Parkhurst. Its assignment structure supports learners when managing their learning tasks, thus triggering self-organized acquisition of knowledge, and its feedback graphs enable transparent learning processes. Since e-learning environments have become common use, rather than creating another system, we propose a modular approach that can be used for extending existing e-learning environments. In order to design a respective component, we interviewed experts in self-organized e-learning. Their input facilitated integrating the Dalton Plan with existing features of e-learning environments. After representing each interview in concept maps, we were able to aggregate them for deriving e-learning requirements conform to the Dalton Plan instruments. In the course of implementing them, particular attention had to be paid to the asynchrony of interaction during runtime. Java Server Faces technology enable the Dalton Plan component to be migrated into existing web 2.0 e-learning platforms. The result was evaluated based on the acquired concept maps, as they also captured the transformation process of the Dalton Plan to e-learning features. The findings encourage embodying further progressive education approaches in this way, since the structured (concept) mapping of the Dalton Plan to e-learning features turned out to be accurate. The experts were able to recognize the potential of the approach both in terms of structuring the knowledge acquisition process, and in terms of developing
\end{abstract}


progressive learning support features.

Keywords: e-Learning; Progressive education; Dalton Plan; Concept mapping; Web 2.0

Biographical notes: Georg Weichhart is senior researcher and head of the Flexible Production Systems team at PROFACTOR GmbH. He is area manager at the research centre Pro2Future working on the topics cognitive robotics and shop floors. At IFAC, he chairs the technical committee on enterprise integration and networking. More information can be found here: https://www.profactor.at/en/research/industrial-assistive-systems/flexibleproduction-systems/

Christian Stary is full professor of business information systems with the University of Linz. His current research interests include the area of interactive distributed systems, with a strong focus on method-driven learning and explication technologies for personal capacity building and organizational development. More can be found here: http://www.jku.at/ce/

Markus Appel is a psychologist and full professor of media communication at the University of Würzburg. $\mathrm{He}$ is interested in the psychology of communication and media, including questions on learning and education in a digital world. More can be found here: http://www.mcm.uniwuerzburg.de/en/arbeitsbereiche/media_communication/

\section{Introduction}

The internet provides a high number of information sources, storing detailed information for self-organised learners. However, a taxonomy for learning objectives (Anderson et al., 2001; Bloom, Engelhart, Furst, Hill, \& Krathwohl, 1956) reveals that the ability to remember knowledge is the lowest level of competence, and the ability to create new knowledge is the highest level of competence (Krathwohl, 2002). For allowing students to acquire this kind of knowledge, learning environments are required that do not only deliver content to students, but that empower them to make use of inquiry-based methods for self-driven problem solving.

Modern teaching approaches, based on constructivist learning principles, show the most promising results in terms of long-term knowledge acquisition (Davis, Smith, \& Leflore, 2008; De Jong et al., 2012). Constructivist learning theories place the active learner in the centre of their considerations. This focus requires a motivating learning environment supporting the learners individually or in groups, to analyse problems, construct new knowledge, and apply this knowledge for open-ended and creative problem solving (Stary \& Weichhart, 2012; Casanova, Moreira, \& Costa, 2011; Yuan, Wang, Kushniruk, \& Peng, 2016). Progressive education approaches (also known as reformist pedagogies) have developed methods to improve the self-organised acquisition of theoretical knowledge and practical skills before the rise of constructivist learning theories (Eichelberger, Laner, Kohlberg, Stary, \& Stary, 2008). They, however, share elements and goals with constructivist principles (Auinger \& Stary, 2005).

The Dalton Plan, one of the most prominent reformist approaches (van der Ploeg, 2013) has been developed by Helen Parkhurst in the 1920s and is aiming to 'balance individual needs with societal demands. In the spirit of progressivism, the teaching was 
based on the student's interest and a respect for others and their needs. It implied working together, towards individualized goals.' (Lundgren, 2014, p.38). The Dalton Plan was subsequently implemented in Dalton, Massachusetts, and New York City (Shrock, 1995). It triggered restructuring a (secondary) school day into subject labs. Students started making monthly contracts and determining their daily assignments and schedules (Edwards, 1991; Popp, 2002). The Dalton Plan became a model concept for societal design (cf. Lee, 2002) and schools in Europe, in particular in the Netherlands, leading to 400 Dalton schools (van de Ploeg, 2014).

According to van der Ploeg (2013), the Dalton Plan still drives educational reforms in several countries. Recognizing the needs of a multicultural society the Dalton Plan reconfirms learner-centeredness in education (Semel, 1992). Accounting for institutional settings (Tyack \& Tobin, 1994), it provides role models for individualised instruction, individual assignments, differentiation, self-direction, self-pacing, freedom, tutor learning and co-operation. The Dalton Plan enables individualized learning within a mass-education system through a combination of flexible scheduled assignments, and individualized evaluation of achievements (Cohen, 1988).

According to Helen Parkhurst, the school as a community of working students and teachers educates learners in terms of jobs and contracts of schoolwork. By placing the work in their own hands, students take on educational work. The efficiency of learning increases when students are given more responsibility for what they are doing, how they are doing it and when they are doing it (cf. van de Ploeg, 2014). As they can decide what and how they achieve their target, learners construct their mental models and knowledge according to their capabilities and under their control within in the school community - social constructivist learning processes are triggered.

Although the Dalton Plan has proven to be not particularly original, since "Parkhurst recycled various ideas and methods which had already been developed and tried out in the preceding decades" (van de Ploeg, 2013, p. 314), its profits stem from its extensive use in education (cf. Lee, 2000; Mödritscher, Garcia-Barrios, \& Gütl, 2004; Shrock, 1995; Sorokin, \& Elena, 2016). Hence, it seems to be worthwhile to review its capabilities in light of these experiences. Since e-learning developments are rather common in many educational institutions, of particular interest is the modular enrichment of existing learning support systems. It could accelerate the embodiment of pedagogical findings into e-learning.

In the following, we enrich an existing e-learning environment with the Dalton plan. We provide empirical foundation by interviewing e-learning experts in selforganized learning support. These interviews provide relevant design inputs which need to be considered in addition to architectural or technological issues. Moreover, they provide a frame for evaluating the implementation of the Dalton plan in e-learning environments.

The paper is structured as follows: First, we introduce the Dalton Plan. Secondly, we report on interviewing e-learning experts on self-organized learning and acquisition of knowledge in terms of problem-solving competencies. We proceed with design and implementation in an existing e-learning platform. Finally, we discuss the evaluation of the implementation, before concluding with our achievements and topics for further research. 


\section{The Dalton Laboratory Plan}

The Dalton (Laboratory) Plan (Parkhurst, 1923, 2010) has been developed from practical experience facilitating self-organized learning in the classroom (Eichelberger, 2002). The overall goal is to set explicit learning goals and motivate learners to allow students to actively immerse in a topic. Learning objectives are explicitly stated, as the Dalton Plan approach places itself in the middle of the continuum between teacher-centred approaches, where teachers convey the "objective" truth, and approaches in which learners work independently without guidance to acquire knowledge.

To support the realisation of these principles, two pedagogical instruments have been developed for the Dalton Plan:

- Assignments and

- Feedback - Graphs.

The objective for using assignments is to structure individual and group learning processes by making explicit what needs to be done. At the same time, freedom is given to the learners in order to stipulate the development of individual and group problemsolving skills by not giving any requirement how the tasks are done, but how the work should be documented (Konrad \& Traub, 1999; Parkhurst, 1923, 2010). In more detail, the assignment structure consists of the following parts to structure the learning process (in tasks) and help students managing their activities. The orientation section (preface) motivates learning by linking classroom activities to real-world challenges. The topic section clearly states the objectives of the learning activities. The problems section provides larger tasks that need to be executed by the student. These tasks should address different skill levels. The written work section captures the form in which the learning activities are documented. The memory work section reminds the student of the cognitive tasks that need to be fulfilled for being able to reach the objectives. The conferences section lists the meetings where students meet and discuss (with/without the teacher) the tasks of the assignment. The references section lists background literature that is helpful for the tasks at hand. The equivalents section documents the organisational effort expected (similar what are now ECTS credits). The bulletin study section points to a place where students find updated information. The departmental cuts section shows when assignments and the equivalents address different classes like history and English together. Feedback - Graphs serve to make learning outcomes explicit and transparent to learners and teachers. Parkhurst has proposed different views captured in different graphs to make the progress of learning transparent to students and teachers. Each graph-form consists of lines determining the progress (from bottom to top of the form) either for each subject of a particular student, or for each student of a certain topic. Explicit feedback supports self-organised learning management by students (Auinger \& Stary, 2005; Chiu \& Li, 2016). Fig. 1 shows feedback-graphs highlighting the learning progress from a teaching-subject point of view (back) and a student's point of view (front).

\subsection{Challenges and opportunities}

Electronic learning environments provide a rich set of opportunities for enabling studentcentred and self-organised knowledge acquisition (Friedman \& Deek, 2003). e-Learning environments supporting autonomous learners are effective (De Jong et al., 2012; Chiu \& Li, 2016; Imran, Cheikh, \& Kowalski, 2016; Yuan et al., 2016) and efficient (Auinger \& Stary, 2005; Li et al., 2016, Stary, 2016). To transpose this potential both, the teaching approach and the technical infrastructure have to be considered. 
"The effective use of technology in education, however, is not instantaneous and must take into account that it must be used with thoughtful planning, design, reflection and testing" (Casanova, Moreira, \& Costa, 2011, p. 895)

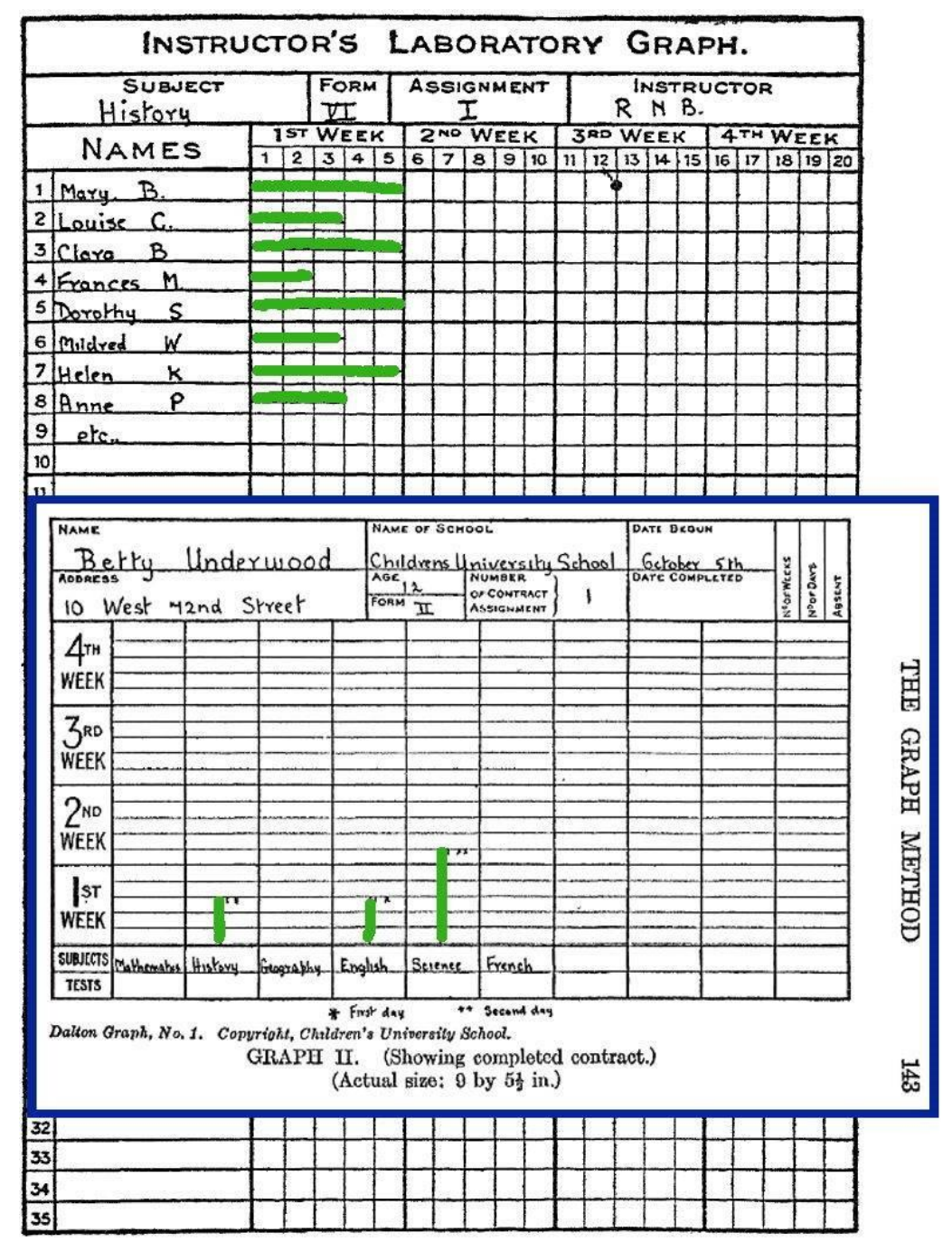

Fig. 1. Feedback-graphs according to the Dalton Plan. Adapted from Parkhurst (1923, 2010)

Research suggests that the use of the Dalton Plan instruments in e-learning creates opportunities but also faces some challenges (Weichhart, 2014):

- $\quad$ Potential for self-organized learning: e-Learning technologies facilitate selforganized learning effectively and efficiently (Auinger \& Stary, 2005; Friedman \& Deek, 2003; De Jong et al., 2012). Reform pedagogies (such as the Dalton Plan) provide a setting that also promotes self-organization (Eichelberger et al., 2008). Combining both carries a high potential for facilitating self-organized learning. 
- Missing support for education using self-organisation: Most teachers today have made their own learning experiences in traditional learning environments. In progressive pedagogy both, the role of the teacher and the methods used, stand in contrast to traditional approaches. Teachers cannot rely on their own learning experiences when planning their own teaching (Lillard, 2007). In addition, the use of e-learning technology requires new skills. To acquire these skills support is required.

- Lack of implementation of the Dalton Plan in e-learning: In the domain of elearning several researchers noted that the integration of pedagogies is missing (MacDonald \& Thompson, 2005; Pange \& Pange, 2011; Zardas, 2008). More specific, there is no support for all instruments of the Dalton Plan. The creation of assignments requires great effort for preparation by teachers (Hackl, 2002). The application of the graph method requires additional effort. Technical support for teachers in the use of the Dalton Plan in e-learning is missing.

\subsection{Research objectives}

In order to realize the above potentials, we aim to transfer the Dalton Plan instruments into e-learning, to support teachers in creating a learning environment that facilitates selforganized knowledge acquisition. This objective shows two aspects:

- $\quad$ Transferability of the Dalton Plan instruments into e-learning: Understanding the requirements and realising of a comprehensive implementation of Dalton Plan instruments in e-learning. The Dalton Plan instruments will be realised as software components. The quality of goal-achievement is determined by the process supporting the Dalton Plan in an e-learning environment.

- e-Learning support for the transfer of knowledge through self-organized learning: The e-learning environment has to support teachers to prepare a learning environment for self-organised knowledge transfer and acquisition. The achievement of this goal is measured through the quality of support for Parkhurst's principles (freedom, creativity, community, and self-employment). This aspect is dealing with the usefulness of researched methods and technologies to support knowledge acquisition and knowledge by means of selforganized learning.

\section{Reconstruction and analysis of existing user knowledge}

For understanding the user's needs and requirements for methodological and software support we first reviewed the scientific literature.

\subsection{Literature review}

Empirical results reveal not only the importance of self-organised learning (Mooij, 2009), but rather that both, computer systems and "learning contracts" (Dalton Plan assignments are contracts) are supporting self-organised learning (Lemieux, 2001). Eichelberger et al. (2008) discussed several progressive education approaches. They also introduced a learning platform supporting constructivist learning. The platform is rather generic and does not encode any pedagogy in its full extent. It does not support teachers when following a particular pedagogy. The Intelligibility Catcher (IC) approach uses assignments with a similar, but more focused structure to e-learning (compared to Dalton 
Plan assignments) (Stary, 2007, 2009). These ICs require the teacher or facilitator to consider the use of technology features at design time and highlight them in the ICs. So far, ICs have not been integrated in any electronic platform supporting their execution directly.

Neuhauser and Wittwer $(2002,2008)$ discuss the COoperative Open Learning (COOL) approach, which also builds on the Dalton Plan pedagogy. They developed some e-learning support features, utilizing the e-portfolio component of the moodle platform (www.moodle.org). Although, no direct support for writing and using Dalton Plan assignments is provided - the assignments are text documents, as in the case of the aforementioned ICs - COOL represents a learner -centered way of education even for challenges resulting from high student heterogeneity in the classes. Individualization and differentiation, empathy, and support of cooperative learning enable students to develop individual learning strategies and metacognitive capabilities (Helm, 2014).

However, feedback graphs are not supported by any of the identified approaches. Overall, the results of the literature research are of limited relevance, as so far, no integration of the Dalton Plan instruments with existing features of e-learning environment has been investigated and documented in the scientific literature.

\subsection{Expert interviews}

Due to the lack of explicit knowledge about the use of Dalton Plan instruments and principles in e-learning, there is a need to reconstruct knowledge empirically to fulfil the need for integrating pedagogical knowledge in software and method development (Baxter \& Sommerville, 2011; Pange \& Pange, 2011; Pankowska, 2012; Lindgaard et al., 2006). Unfortunately, existing user centred design methods and software design \& engineering methods are not integrated and often not even compatible (Nebe \& Zimmermann, 2007).

A qualitative empirical method is needed for the reconstruction of knowledge. Expert interviews are a valuable method, for exploring existing conceptualizations in a new field (Bogner \& Menz, 2002; Pfadenhauer, 2002). Expert interviews aim at eliciting and explicating concepts and their structural relationships and allow analysing them in a contextual manner (Meuser \& Nagel, 2002). Software developers and researchers are focusing on user needs (in this particular case teacher's needs) rather than development requirements (Islam \& Omasreiter, 2005; Mayring, 2002), and analysing (conceptual) structures and relationships of complex subjects (Meuser \& Nagel, 2002). People that qualify as experts, have a high level of authority with respect to the researched topic. In this case progressive education in general, the Dalton Plan in particular and e-learning. Additionally, the experts need to be skilled in communicating knowledge in a structured manner (Bogner \& Menz, 2002). In our case, this has to be demonstrated by having publications in the field of e-learning and having given lectures making use of e-learning technologies.

By setting the requirements high, we aimed at getting high qualitative feedback; however, on the other hand we were only able to identify five experts, which we were able to contact. From these contacted, 3 have been willing to participate in our research. This is not a strong limitation, as in this qualitative research, we aim at exploring the domain of interest, providing scientific ground for research to follow.

The literature recommends the use of a field manual with prepared questions that guide the flow of the interview (Bogner \& Menz, 2002). The manual of our interviews has the following parts with 2-3 items for each part: 
- Background Knowledge: In the first part, the expert is asked to identify her/his expertise with respect to assignments, the Dalton Plan, and e-learning.

- Goals: The expert is asked to clarify why the Dalton Plan or assignments (in general) are used and why an e-learning environment is used when he/she is teaching. If possible the usefulness of existing instruments should be discussed.

- Self-organised learning: Do the used instruments and technologies support or restrain self-organised learning?

- Monitoring and Feedback: The expert is asked to discuss possibilities and efforts for monitoring the progress of the students and how feedback is handled using existing methods and tools.

- Effectiveness and Efficiency: Experts identify potentials for improving the effectiveness and efficiency of the used approach and tools.

- Integration of pedagogical approaches in e-learning: Do the experts know whether and how a similar pedagogical approach has been integrated into elearning settings?

Within a period of 3 months, the interviews could be completed. Two of the interviews have been done at the offices of the experts; one interview has been conducted using a standard voice over IP software tool. The interviews took between 60 and 90 minutes and were recorded for analysis.

\subsection{Analysis and validation of qualitative interviews}

For analysing and validating the recorded interviews, several options have been considered. The literature has identified that graphical tools often lead to results closer to formal models. Such approaches improve the overview of the communication between author and user of the model. Graphical models also improve the visibility of gaps and inconsistencies in the mental models (Bortz \& Döring, 2002). We considered the following languages for the interview analysis:

- $\quad$ UML Use Case

- $\quad$ Argument Maps

- $\quad$ Mind Maps

- Knowledge Maps

- $\quad$ Concept Maps

We have evaluated these according to the criteria in Table 1.

We concluded that for our work concept maps following the approach of Novak and Cañas (2008) are most suitable for capturing the essence of the theories presented by the experts in the interviews (Weichhart, 2012). We have therefore modelled the results of each interview using concept mapping, supported by the CMap tool (Cañas et al., 2005).

A concept map in this approach consists of two elements concepts and propositions. The former is represented in the maps typically rectangles. Propositions are the combination of two concepts connected with a labelled arrow. A proposition should be readable:

$$
\text { [concept]-is-related-to- }>\text { [concept] }
$$


Table 1

Criteria for selecting an interview analysis approach

\begin{tabular}{|c|c|}
\hline Criteria & Description \\
\hline $\begin{array}{c}\text { Graphical } \\
\text { Representation }\end{array}$ & $\begin{array}{l}\text { The possibility to model graphically should facilitate } \\
\text { capturing and transferring knowledge. }\end{array}$ \\
\hline $\begin{array}{l}\text { Concise } \\
\text { Representation of } \\
\text { Knowledge }\end{array}$ & $\begin{array}{l}\text { In order to facilitate the transformation of captured } \\
\text { knowledge structures into software, the approach has to } \\
\text { enable modelling in a semi-formal manner. }\end{array}$ \\
\hline $\begin{array}{l}\text { Representation of } \\
\text { Complexity }\end{array}$ & $\begin{array}{l}\text { The approach needs to be able to capture complex systems } \\
\text { in order to allow knowledge transfer from the research } \\
\text { subject to the researcher. }\end{array}$ \\
\hline $\begin{array}{l}\text { Simple use (and tool } \\
\text { support) }\end{array}$ & $\begin{array}{l}\text { To allow domain experts to participate in the process and } \\
\text { support understanding and validation of models, created by } \\
\text { the researcher, it is necessary to find a method that requires } \\
\text { no prior knowledge by the domain experts. Furthermore, for } \\
\text { efficiency reasons, tool support is desirable. }\end{array}$ \\
\hline
\end{tabular}

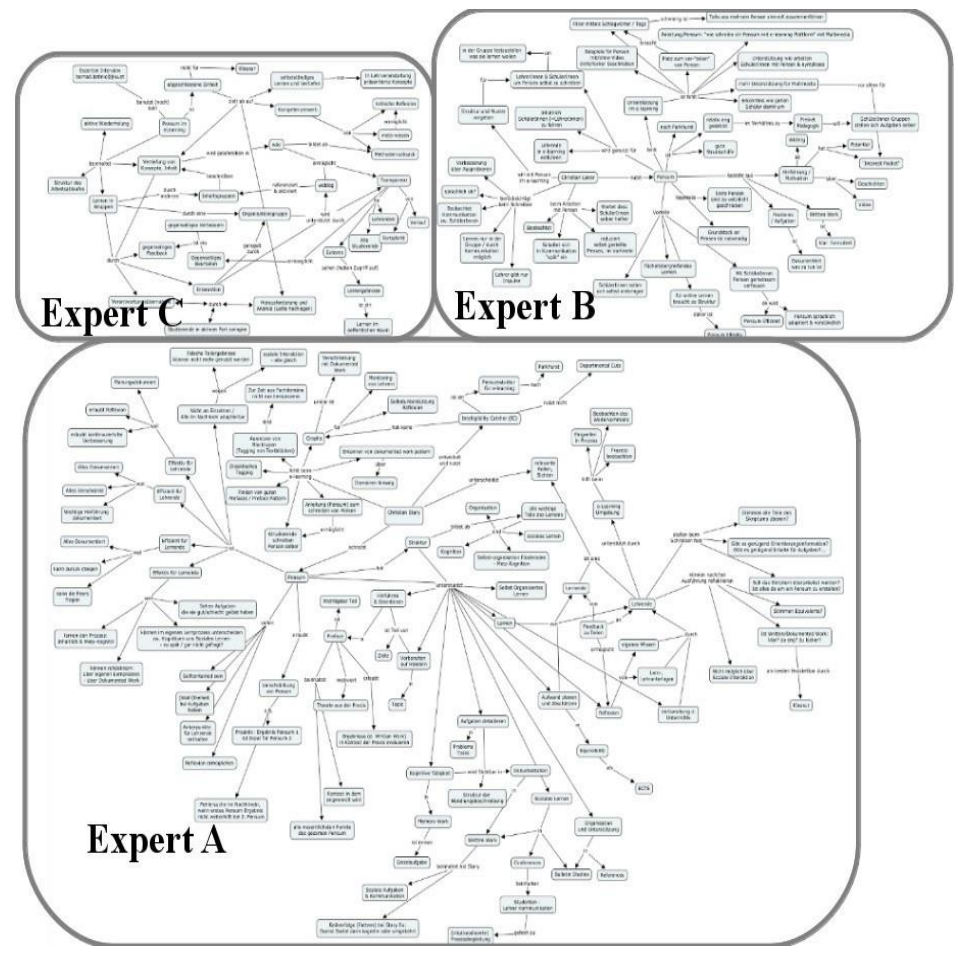

Fig. 2. Structural comparison of concept maps from the interviews

The analysis is followed by validating that analysis. The validity of a research result is one of the most important criteria for research (Bortz \& Döring, 2002; Mayring, 2002). In the field of qualitative research, the broad consensus between research subject 
and researcher is of importance. The method of communicative validation allows the researcher to present the researched subject (in this case the interviewed experts) the result. If the experts agree on the documented results of the interviews, a high level of validity may be assumed.

The results are captured as concept maps. Each expert has been presented the mapped results of his/her interview, hereby asking the experts to validate the results on a communicative basis.

Fig. 2 provides a structural comparison of the concept maps. By intention, the concepts are not readable to visualise the maps' structures. One of the maps has been rearranged to fit the paper format and is presented in Fig. 3.

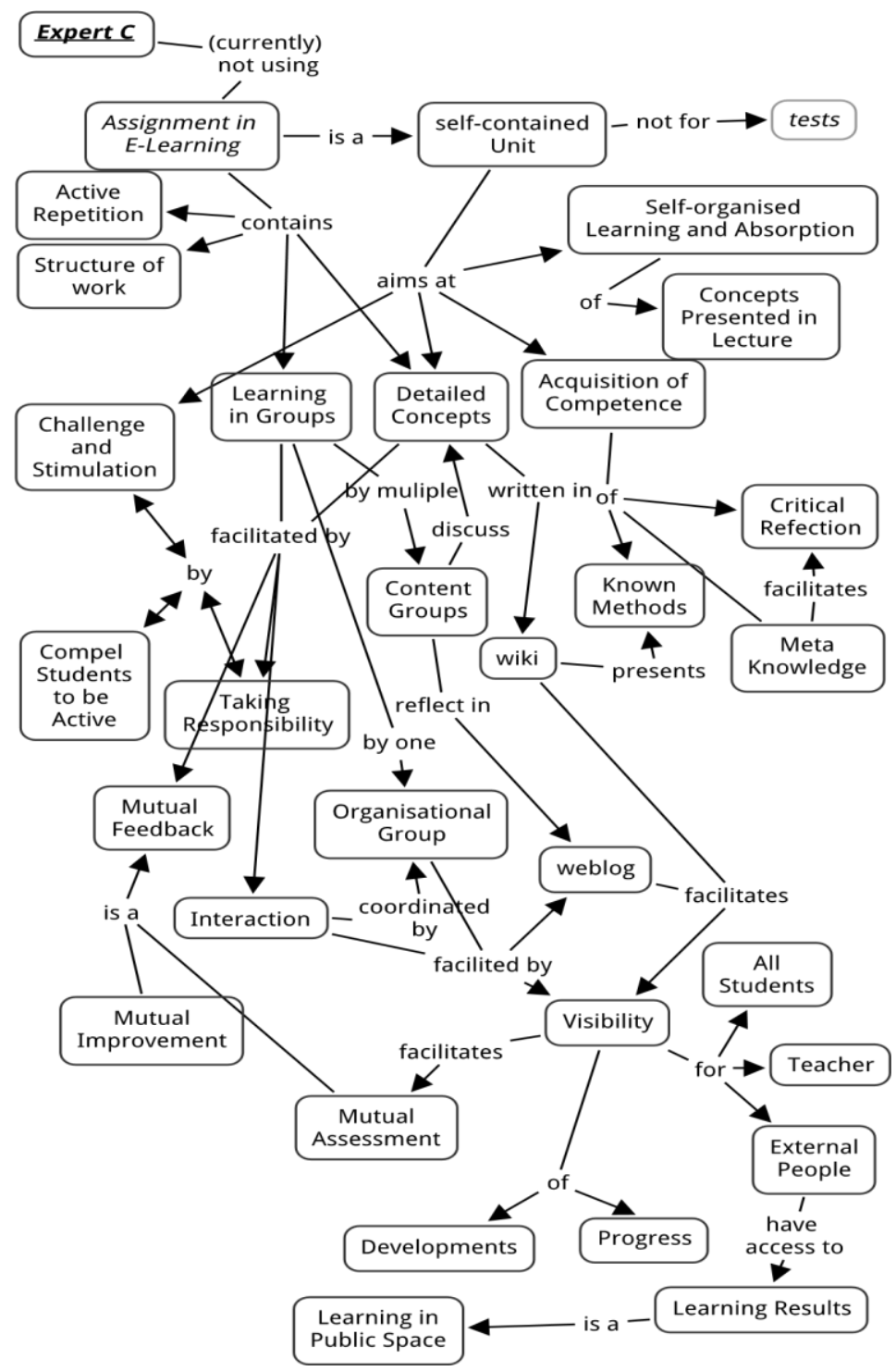

Fig. 3. Details of expert C's map created from the interview 
The first expert (upper left map) has not worked with the Dalton-Plan before. However, he has worked (and published) in the domain of e-learning and worked with assignments (but not according to the Dalton Plan). This missing experience is reflected by the fact that no concepts related to planning are given in the interview. Being a psychologist and teacher, most concepts relate to the learning tasks and the execution of the assignments. The second expert (upper right map) has worked with the Dalton-Plan. $\mathrm{He}$ is a teacher and trained e-learning manager and therefore provides some insight into the usage of information systems. He is also working with a related progressive educational approach, created by Célestin Freinet (Skiera, 2003). In this approach learning tasks are planned by the students themselves. Several remarks during the interview were related to this approach where planning and learning are joint activities. The third expert (bottom map) has worked with the Dalton-Plan. He performs research in the field of e-learning and progressive education. This experience allows him detailing the topics in the interview along multiple dimensions. It is reflected by the fact that this map holds the highest number of concepts. The map is detailed and highly structured.

\section{Requirements engineering}

The literature stresses the importance of socio-technical approaches in the development of systems, since these approaches enable technical systems with higher acceptance rate (Baxter \& Sommerville, 2011). Developers need an understanding of user's point of view to gain acceptance. With respect to technical e-learning systems, software features are in the focus during development and pedagogical aspects are mostly ignored (Casanova, Moreira, \& Costa, 2011; Pange \& Pange, 2011). Moreover, today's software design and engineering methods are not compatible with User Centred Design methods (Nebe \& Zimmermann, 2007). In the following, we describe a novel concept-map based method that allows transparently transferring end-user knowledge to the design and engineering activities.

\subsection{Aggregation of individual views}

The validated results (concept maps) of the interviews provide three individual, independent and subjective views. These individual views need to be aggregated to provide a single requirements base. However, different aspects or categories of analysing need to be respected to meet the research goals.

The method "Construction of Descriptive Systems" (Mayring, 2002) enables aligning the planned analysis categories derived from the research objectives and the categories identified by the experts. It explores the border between top-down theory driven research and bottom-up empirical research (Mayring, 2002).

Applying the method leads to the following process for constructing a set of categories. Based on the objectives of this work, namely to transfer the Dalton Plan instruments into e-learning environments while supporting learning processes by means of self-organization, we have derived the following categories a-priori:

- $\quad$ Structures of assignments and feedback graphs in e-learning

- $\quad$ Process of creating and improving assignments

- $\quad$ Processes of students learning using Dalton Plan instruments 
Going through the materials we discovered the following additional categories:

- General requirements to the e-learning system

- Teaching by letting students write their own assignments

- Other (This category will be omitted in the following as it holds irrelevant concepts and propositions)

orials etc. As an impor.

Concepts and propositions in the expert's concept maps are categorised in the following way:

- $\quad$ Structure: Dalton Plan assignment structure

- Students' Learning: learning with assignments; monitoring using the Graph Method; communication among students; communication of students with facilitator when learning

- Creating Assignments: design, writing, and improving assignments

- Assignments done by students: students planning their time; students writing their own assignments

- General requirements: general aspects related to learning

- Other Concepts: concepts irrelevant to the work at hand. contains.

Table 2 provides a quantitative overview of the percentage of concepts each map

Table 2

Quantitative comparison of maps: Categorisation of concepts (Expert Map in Fig. 1)

\begin{tabular}{rrrrr}
\hline Category & $\begin{array}{r}\text { Upper } \\
\text { Left }\end{array}$ & $\begin{array}{r}\text { Upper } \\
\text { Right }\end{array}$ & Bottom & \% of Concepts \\
\hline Structure & $9 \%$ & $14 \%$ & $10 \%$ & $12.5 \%$ \\
Students' Learning & $70 \%$ & $16 \%$ & $15 \%$ & $25 \%$ \\
Creating Assignments & 0 & $31 \%$ & $26 \%$ & $27.72 \%$ \\
Assignments by Students & 0 & $10 \%$ & $2 \%$ & $5.98 \%$ \\
General Requirements & $12 \%$ & $8 \%$ & $10 \%$ & $13.04 \%$ \\
Other Concepts & $9 \%$ & $20 \%$ & $37 \%$ & $15.76 \%$ \\
Total Number of Concepts & 33 & 49 & 102 & \\
\hline
\end{tabular}

Having created categories allows grouping all concepts and propositions belonging to that category into a concept map for each category. The concept map in Fig.4 represents the category structure, holding concepts and propositions from all interviews. Concepts stemming from different experts are marked by the different lines used to frame a concept. Each expert has her/his individual line style. This allows locating each concept within the context of the originating map. 


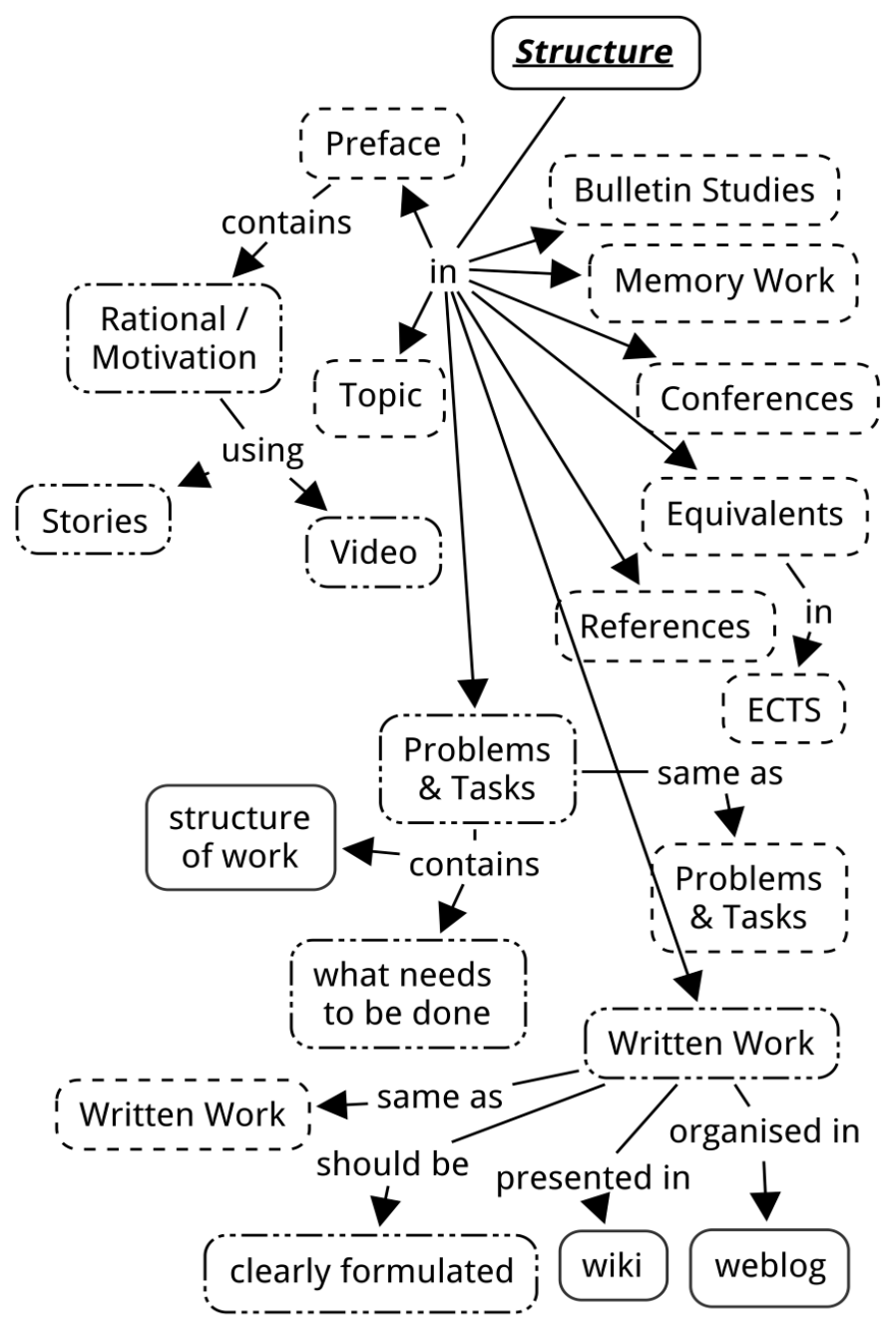

Fig. 4. Category structure: Concepts from all three expert interviews

\subsection{Conceptual user interfaces}

Knowledge on using Dalton Plan instruments within an e-learning environment has now been codified in concept maps along multiple categories. A user interface typically has a different logic where the functionality drives the elements displayed to users.

To include user-interfaces and features to support the use of the Dalton Plan in elearning environments according to the principles of the interviewed experts, we have created concepts that represent conceptual user interfaces. The concept maps of the different categories have been extended to include these conceptual user interfaces. This way it is made explicit, which concepts are supported directly or indirectly by a particular feature. In Fig. 5 the example of the assignment editor is given. It is required that the editor supports all parts of the Dalton Plan assignment. Here the difference between direct and indirect support is shown. The editor should support editing the preface. The editor should also be able to handle videos. The editor does not support directly that the 
preface is motivating. However, videos may be used as multi-media support and thus, for motivating learners.

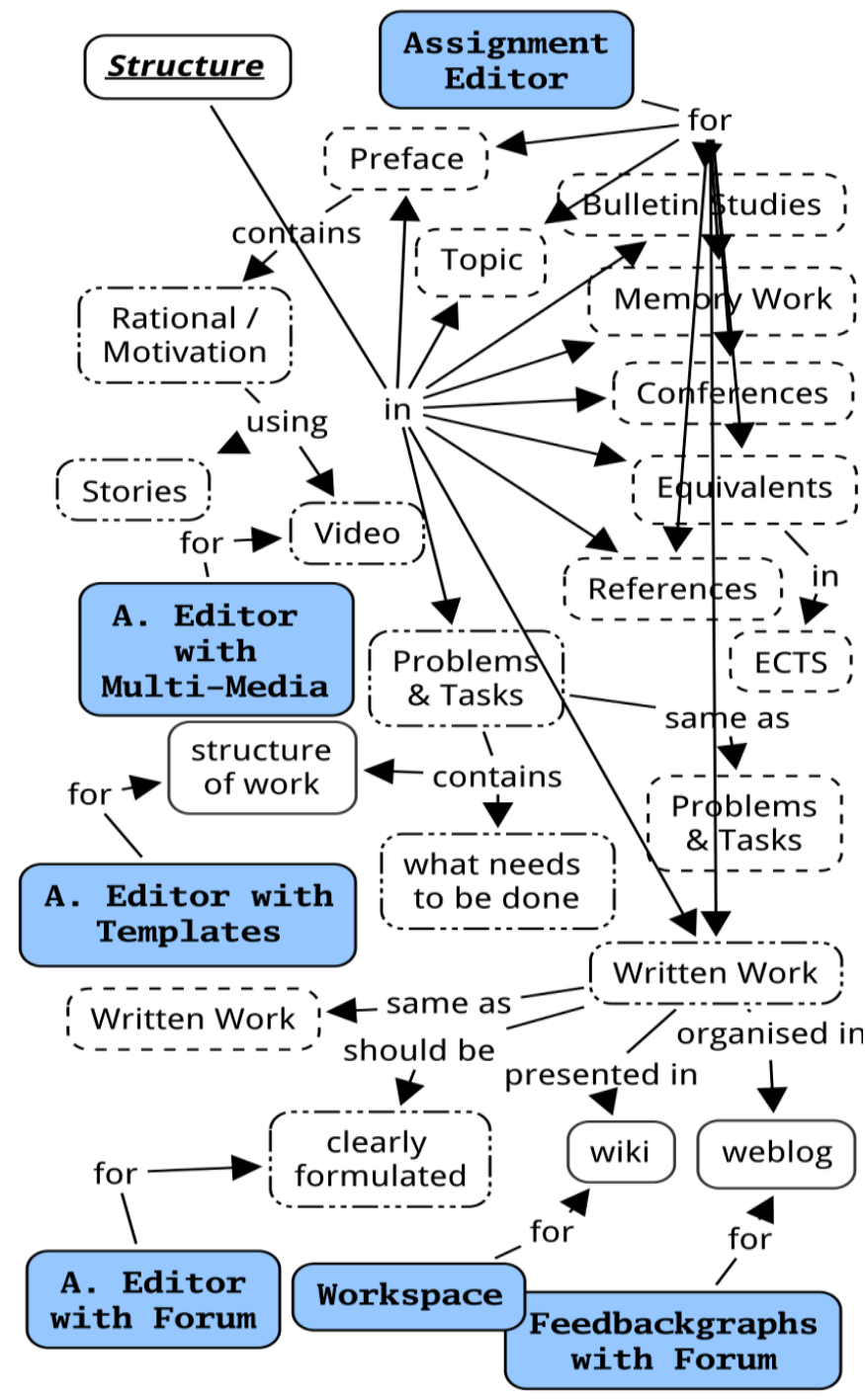

Fig. 5. Conceptual user interfaces for category structure; A. Editor ...Assignment Editor.

We have identified conceptual user interfaces as briefly described below. Since the environment is to be installed in an existing e-learning environment (Scholion 2.0 aka. nymphaea) we have re-used existing functionality.

\subsubsection{Workspace}

The workspace is a Scholion 2.0 concept which provides the main entry point for learners and facilitators or teachers. For each e-learning course at least one workspace is created in the e-learning system. Teachers and students have access to a rich-text editor, which allows them providing seminar papers or lecture notes directly in the platform. The rich- 
text editor allows formatting the content and replaces (even enhances) wiki functionality. Assignments should be accessible within this workspace to allow the re-use of existing features.

\subsubsection{Assignment editor}

For teachers, the assignment editor is of importance. It should support the creation and update of assignments and all parts according to the Dalton Plan. This includes not only the provision of a plain "Text Editor" to write assignments, but also guides users to write applicable assignments.

Discussion Forum Integration: As students might have questions about assignments, it should be possible to link assignment parts to items of a discussion forum. This supports the improvement of the assignment text over time. A discussion forum is even more important when students are collaboratively creating their own assignments.

Multimedia Capabilities: The use of videos is viewed as being valuable for creating motivational prefaces (Dalton Plan orientation sections). Such videos could also support the introduction to writing assignments.

Supporting Templates and Examples: Good / bad examples of assignments with / without video and multimedia support would be helpful for people writing their first assignment. Assignment templates could provide pre-written assignments with only a particular target topic missing. For finding shared templates and examples, a tagging mechanism would be helpful to allow searching for content (e.g. math vs. English) and pedagogical issues (like "3rd grade" assignment, introduction assignment, expert assignment).

\subsubsection{Method-explaining assignments}

It is to be expected that many of today's teachers have been raised in traditional learning environments. An introduction and some methodological support to writing assignments and teaching with the Dalton Plan principles is useful.

\subsubsection{Feedback graphs with meeting support}

The graph method of Parkhurst $(1923,2010)$ is to be supported by the e-learning system. It should also provide the possibility to meet on-line, for discussing the progress of the work. Here also a discussion forum would be one possibility to support the communication. The graphs should be visible to the overall group to provide visibility about the progress made by members of the group. This helps teachers to learn where support is needed to assure timely finalisation of projects.

\subsubsection{Portfolio}

To support learning in public space, a portfolio component would allow students presenting their work on assignments to external people like possible future employers.

\section{Design and implementation}

In the following, we briefly describe the design stages and the following implementation. 


\subsection{Functional design}

The two most important drivers for the design are the conceptual user interfaces capturing pedagogical requirements, and the existing technical environment for integrating a Dalton Plan component.

Starting with the latter, we use the existing Scholion 2.0 infrastructure. It is based on a traditional three-layer architecture for web 2.0 applications. The architecture is shown in Fig. 6. In this figure, the Archimate language (Iacob, Jonkers, Lankhorst, Proper, \& Quartel, 2012) is used, showing the user-interface layer (HTML, AJAX technologies on top of Java Server Faces), the business layer with the logic for controlling each user's UI and the general application logic, and as a third layer the technical infrastructure consisting of Java Server Faces (http://javaserverfaces.java.net), Spring Container (http://projects.spring.io/spring-framework/), Hibernate Data Access (http://hibernate.org/).

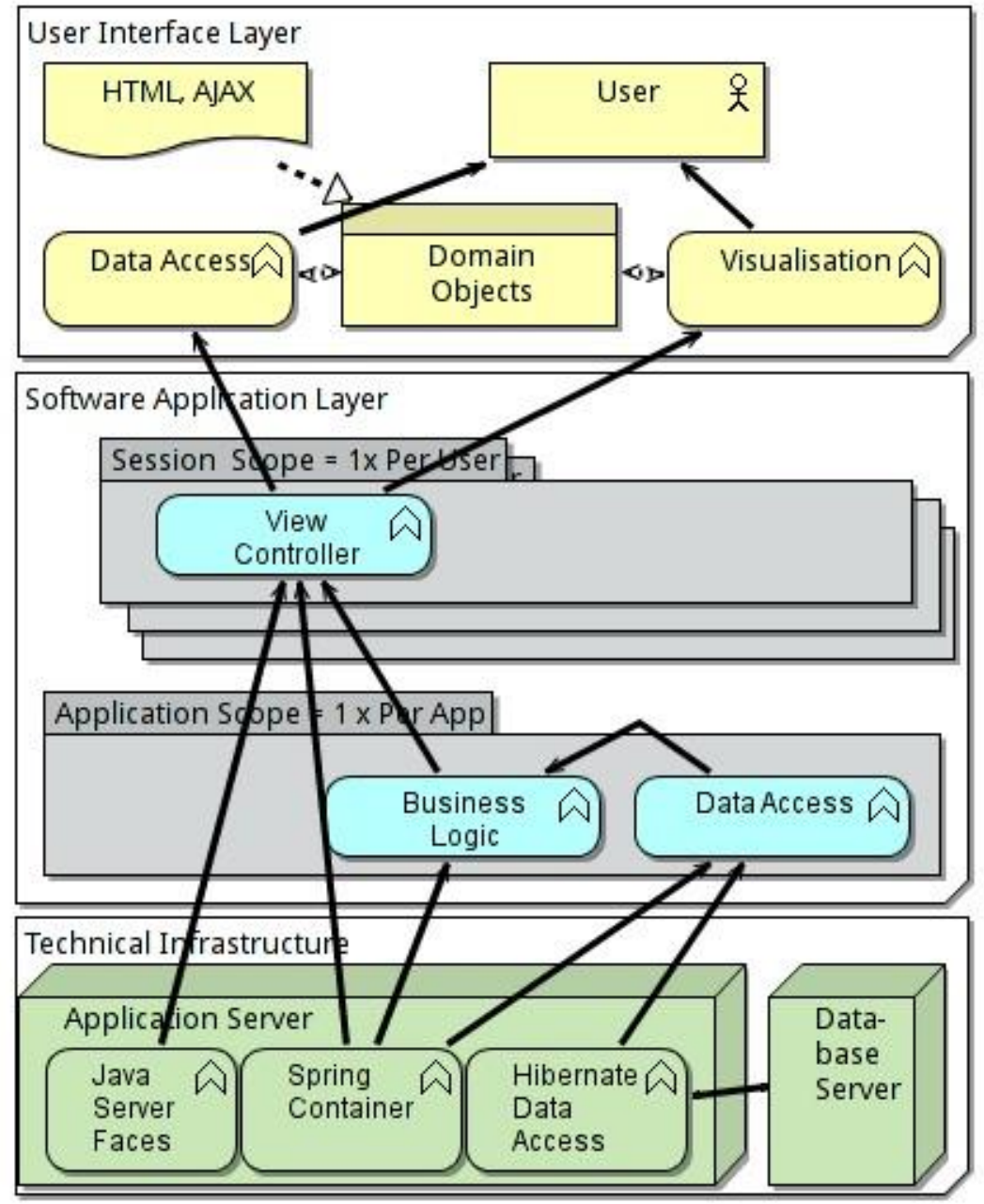

Fig. 6. Abstract architecture of Scholion 2.0 using ArchiMate 
Following the strategy of user-centred design, the design starts with designing a UI (see Fig.7). The detailed design will be based on the Scholion 2.0 look and feel. Following (also) the principle of introducing new concepts in a sparse manner, the detailed design re-uses Scholion 2.0 domain objects where possible.

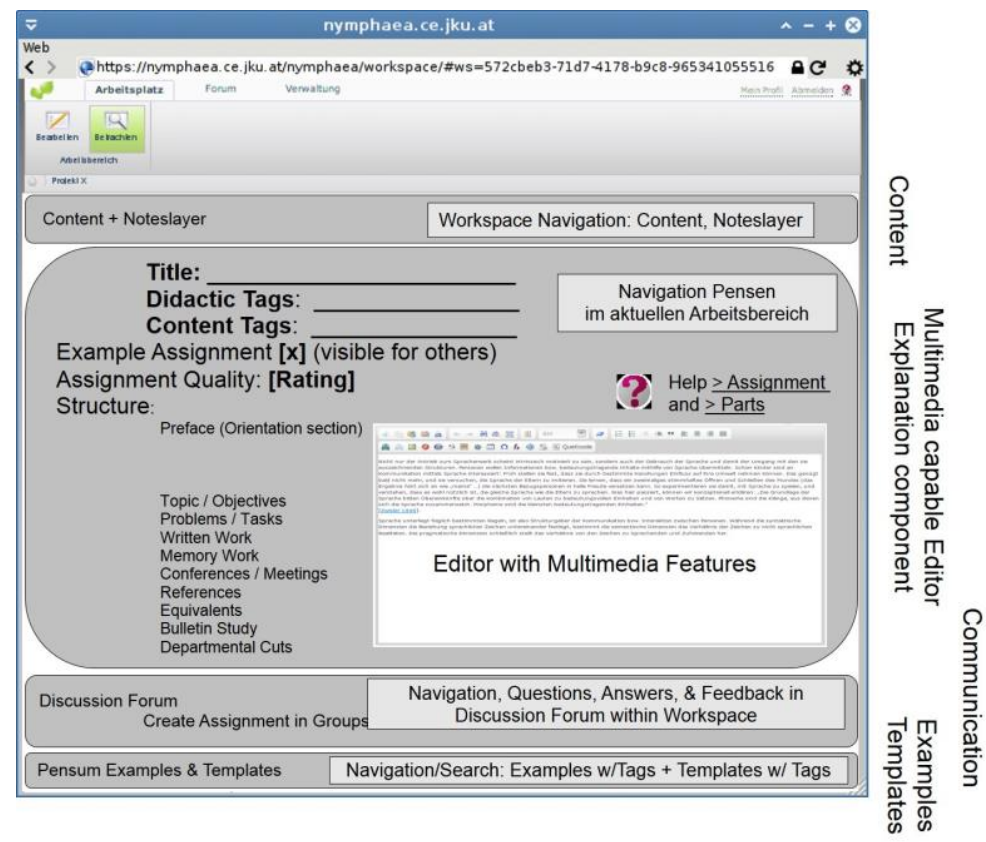

(a) Editor Design

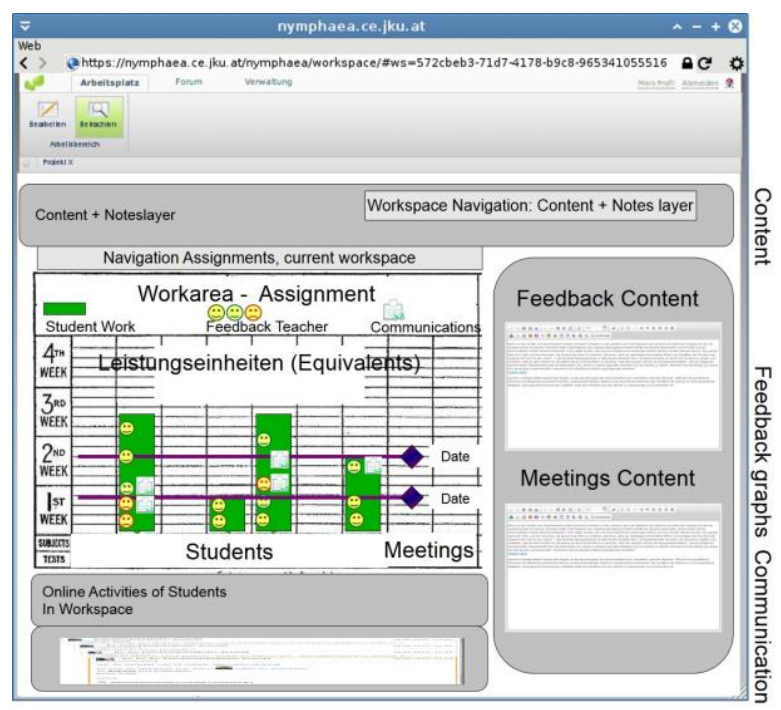

(b) Graphs Design

Fig. 7. Wireframes of Dalton Plan-specific user interfaces 
Part (a) of Fig.7 contains the editor view. On top, a small area provides access to the content. It is necessary to allow users enlarging this area. Here a flexible content box is required, as it is situation-dependent how much of the content should be visible when writing the assignment. The area in the middle is the editor, which allows editing all parts of the Dalton Plan assignment. Visible is a button with a'?' that links to a help component. It is also possible to provide tags for the assignment encoding the pedagogical and content point of view. The two grey boxes on the bottom provide access to a discussion forum required for collaborative writing and to examples and templates. Here, flexible areas are needed enabling users to enlarge an area depending on the situation.

Part (b) of Fig.7 shows the feedback-graph view. On top, a flexible area provides access to the content. In the middle graphs of all students are shown. Each graph has two parts, the green bar allows the students to estimate her/his progress, and the teacher uses emoticons to provide feedback. Additionally, dates for meetings and marks for communication events are placed in the bar-chart figure. On the right side there is a text window containing textual feedback. Descriptions referring to upcoming meetings are displayed. On the bottom a resizable box provides access to the discussion forum.

\subsection{Meta-assignment}

To facilitate novice Dalton Plan users grasping the principles of the Dalton Plan and to help them utilizing the software, a method is needed. As the Dalton Plan is a didactic method for teaching, we decided to base the method on the Dalton Plan itself. The method is named meta-assignment, as it is an assignment on writing assignments. The meta-assignment consists of three parts.

The first meta-assignment introduces the reader to the approach, by positioning the Dalton Plan within progressive education. It provides the motivation and objectives of the Dalton Plan assignments. It is available as a web-based component integrated in the Scholion 2.0 environment.

The second assignment discusses how to get into more and more details when writing assignments. It relates parts, providing some information of what kind of type each part might hold. Throughout this assignment different parts of the software are introduced, and it is demonstrated how the software is used to "document" the work when writing assignments. The third meta-assignment is an assignment, which focuses on the organisational parts of the Dalton Plan.

\subsection{Dalton Plan software components}

The following Dalton Plan support software components have been implemented (in addition to the meta-assignment help system):

- Dalton Plan Editor: This component supports the user in generating the assignment structure including (1) tool bar, (2) content, (3) assignment, (4) discussion forum, and (5) search, as shown in Fig. 8. The Editor is fully integrated in the platform.

- Feedback-Graphs: This component allows the students and the teacher judging the quality of the student's work on the current assignment. It provides possibilities to upload some materials, add a link or free text as result of work on the assignment. The Feedback Graphs component also provides some discussion 
forum like functionality where only users having the role of a teacher and the particular student involved are able to see the discussion (Fig. 9).

- Assignment Management Component: A management component is realised for assigning the teacher or student role to users. In this way it is possible to use the assignment editor by a group of students writing their individual assignment.

The implemented components are fully integrated and have been deployed on a server available to all lecturers and students at Johannes Kepler University, Linz.

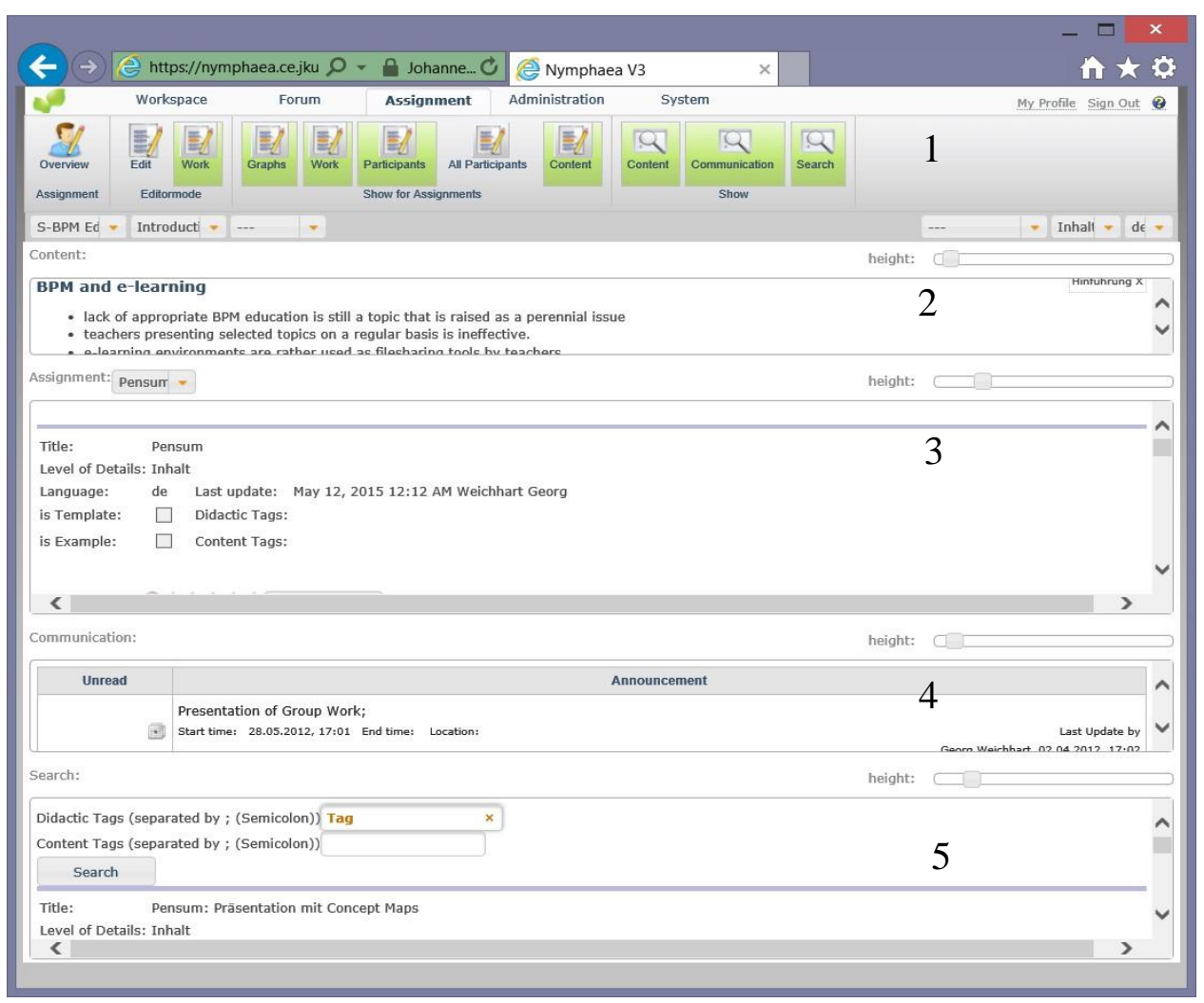

Fig. 8. Assignment editor with multiple view areas. Adapted from Weichhart (2014)

\section{Evaluation}

In order to evaluate the quality of the achievements an empirical evaluation along the following dimensions has been planned and conducted:

- Completeness of the implementation with respect to the Dalton Plan

- Usefulness of the components based on the Dalton Plan intentions

- $\quad$ Support for knowledge acquisition using self-organised learning features

The first dimension is evaluated using the conceptual user interface concept maps of the requirements analysis. The other two dimensions are evaluated through expert interviews involving the experts of the initial requirements analysis. 


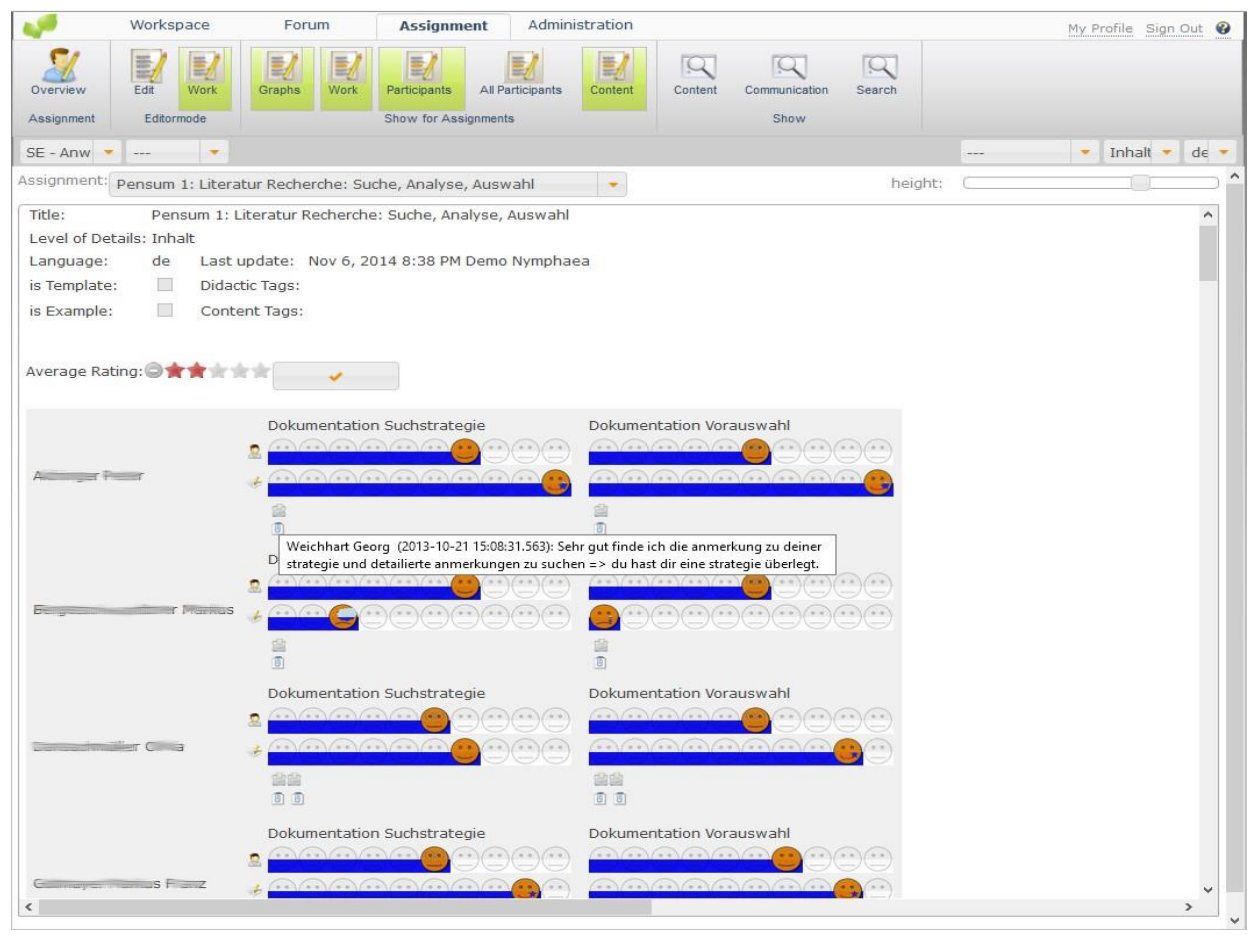

Fig. 9. Feedback graphs showing the work's quality according to the student (upper line) and the teacher (lower line). Adapted from Weichhart (2014)

\subsection{Expert validation}

All experts, who attributed their time to the requirements analysis, had been available to reflect on the implemented results. Again, the method of semi-structured interviews had been used.

\subsubsection{Methodological process}

We adopted the methodological approach from Kandiko and Kinchin (2012b, 2012a), making use of the initial concept maps. All experts validated these maps containing all important aspects of their work with assignments in general, and (where applicable) with the Dalton Plan in particular.

To be able to give a realistic picture on how the software is used, a lecture involving 30 students from a university had been held using the Scholion 2.0 learning environment including the Dalton Plan components. In this way the experts were able to see the Dalton Plan components in-praxi. The following questions had been used to structure the expert inputs:

- Do the developed components meet the requirements of the experts?

- Are all requirements from the initial expert interviews (as documented in the concept maps) fulfilled? Is there any requirement that has been 
misinterpreted? Are there requirements that could only be partially fulfilled? What is missing?

○ Are all presented components (editor, feedback-graphs, metaassignment) useful? How could they be improved?

- Do the developed results support self-organised learning? Are teachers supported according to Dalton Plan principles?

○ to learn to use 'freedom'

$\circ \quad$ to make use of their creative power

- to be able to act as a good member of society

$\circ$ to self-organise

\subsubsection{Empirical validation}

Each interview took roughly 50 minutes. The addressed concepts in the maps have been marked according the expert's interview. In Figs. 10, 11 and in Table 3 results of these evaluations are shown. Fig. 10 provides a graphical impression of the feedbacks by all three experts (based on the Fig. 2 maps). Fig. 11 shows details from the feedback received from expert $\mathrm{C}$ (based on the Fig. 3 map). In these maps, green concepts with a full line show concepts, which the expert considers to be fulfilled. Orange concepts with dashed lines are considered as not fulfilled. Some concepts are statements, which may not be supported (directly). These are blue grey with a full line. These concepts include for example "structure of the work process" and have been recorded in the initial maps but do not need support (if possible). Some concepts in the map are not relevant and are shown in grey in the figures. These include, e.g., the name of the experts. In addition, the experts made comments shown as boxes with square corners and shadows.

Table 3

Results of the interviews; italics line shows how this concept type is represented (Fig. 10)

\begin{tabular}{cccccc}
\hline & Expert A & Expert B & Expert C & $\sum$ & $\%$ \\
\hline $\begin{array}{c}\text { supported concepts } \\
\text { green, full line }\end{array}$ & 57 & 14 & 15 & 86 & 46,74 \\
$\begin{array}{c}\text { not supported concept } \\
\text { orange, dashed line } \\
\text { general concepts } \\
\text { light grey, full line }\end{array}$ & 4 & 6 & 3 & 13 & 7,07 \\
$\begin{array}{c}\text { not relevant concepts } \\
\text { grey }\end{array}$ & 17 & 21 & 12 & 57 & 30,98 \\
total & 102 & 49 & 33 & 184 & 100 \\
\hline
\end{tabular}



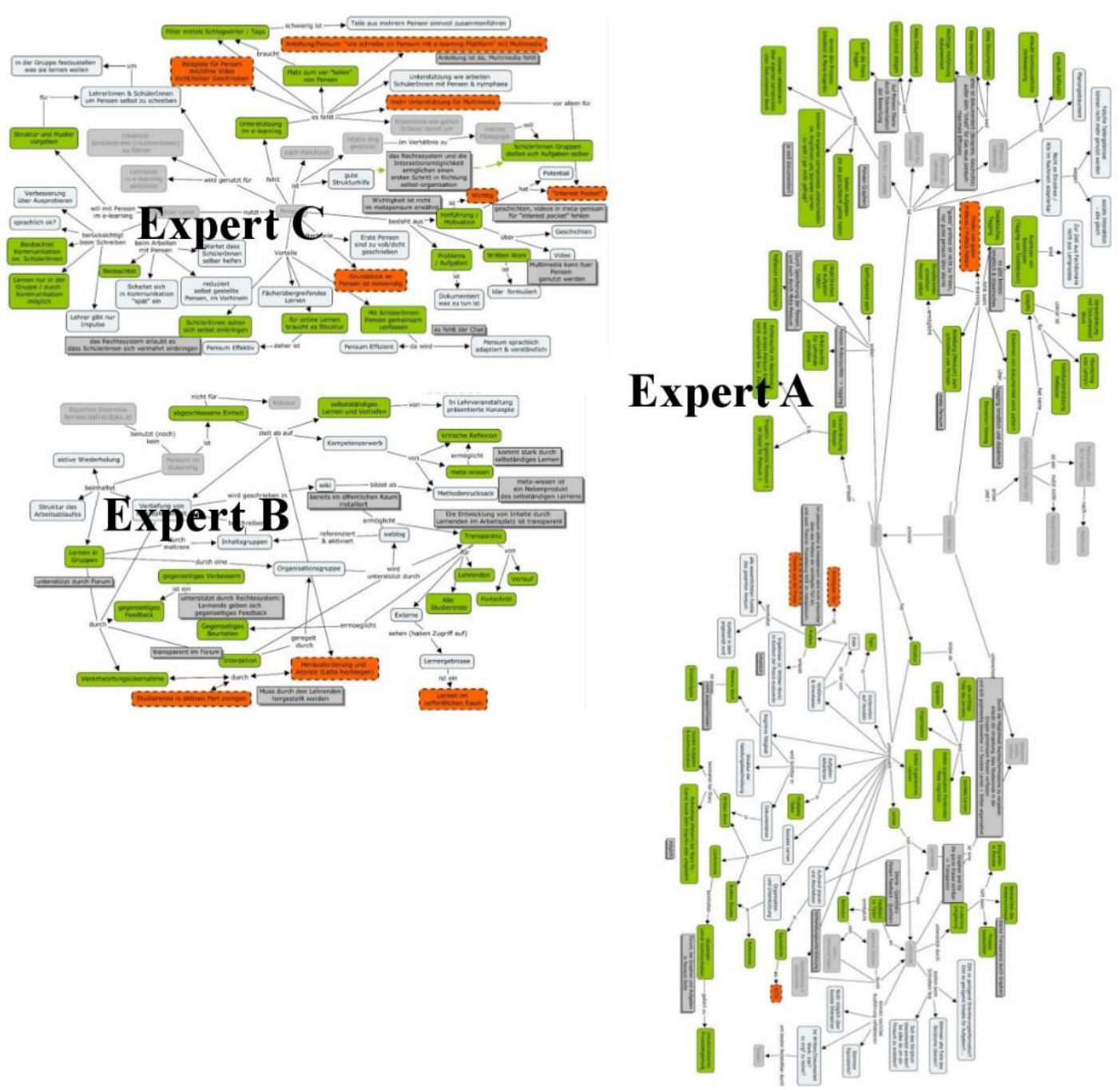

Fig. 10. Structural comparison of results of experts' evaluation

\subsection{Results}

In the following we report on the completeness of the implementation, on its usefulness, and the perceived support of self-organized learning.

\subsubsection{Check of completeness}

Of the 22 identified features, 21 have been implemented. Missing is the possibility to set meeting dates directly in the assignment editor. This feature was available as part of the Scholion 2.0 discussion forum. Due to the required login for users, learning in public areas is not possible. 


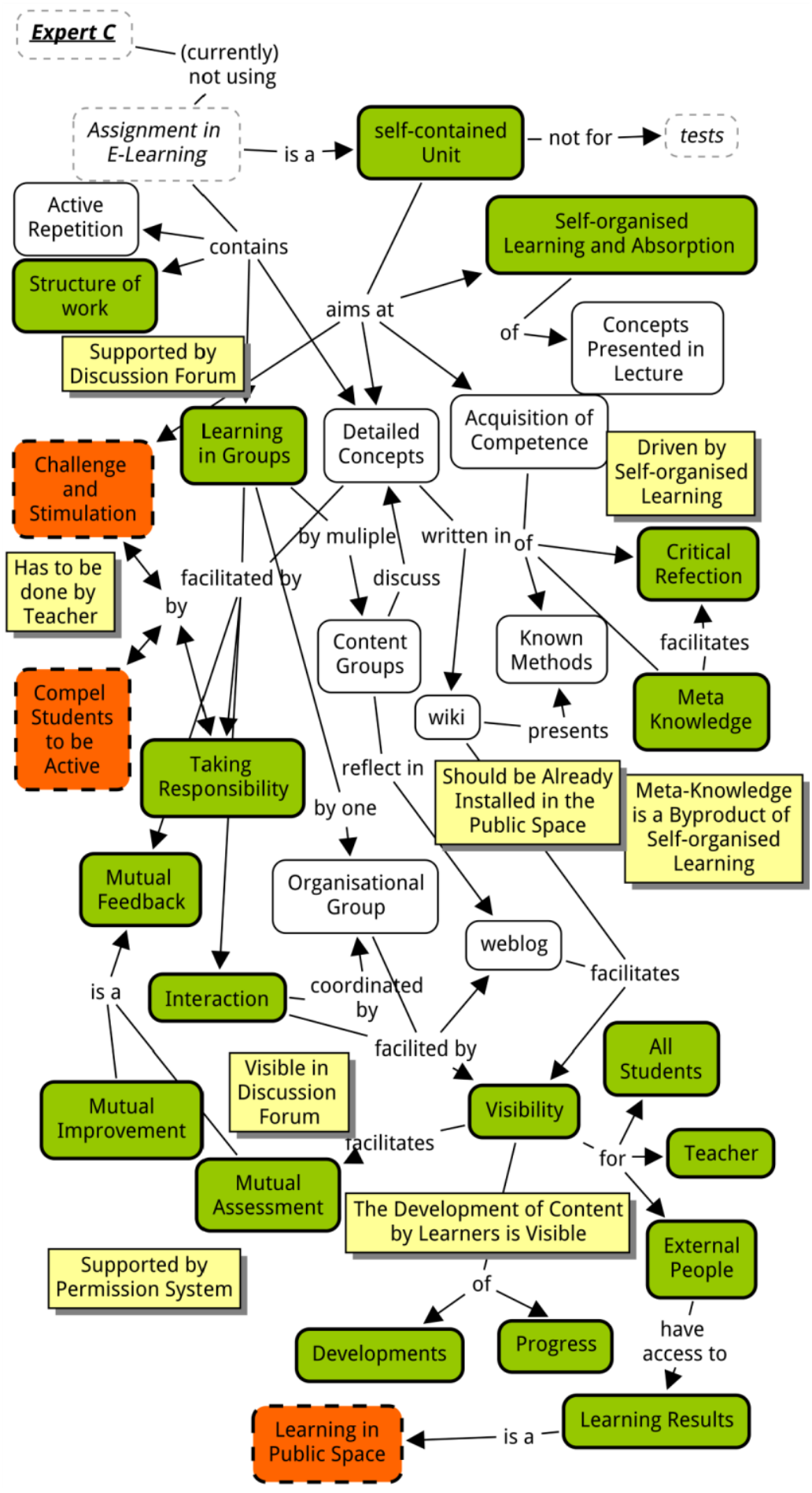

Fig. 11. Evaluation and feedback by expert $C$ 


\subsubsection{Usefulness}

All three experts could at least observe testing the software and the supporting metaassignments. They were impressed by the usefulness of the developed components. The assignment editor might be a bit overloaded for the novice user. However, the possibility to remove some of the views is helpful with respect to that (see Fig. 8: the buttons in (1) may be used to hide or show views 2, 4, 5 but not 3 where the assignment is edited). They also considered useful that it is possible to enlarge or shrink individual views on the editor page using a slider on the side.

With respect to the feedback-graphs, the used emoticons were recognized as an interesting approach by the experts. It is to be evaluated how students react to them. The graphs provide a good overview of the state and the quality of the work. The social, asynchronous, interaction/communication support is considered effective with respect to emphasizing the student's responsibility for acquiring knowledge.

\subsubsection{Support for self-organised learning}

The electronic nature of the supporting environment preserves the contributions of individual students over the time of a course. It makes the individual's behaviour within the learning group highly transparent. This includes the feedback graphs as well as the explicit contributions in the discussion forum of each lecture. As expected, the feedback graphs put higher pressure on individuals (compared to individual feedback), as the individual quality is visible. However, teachers can recognize who needs support.

As mentioned above the asynchronous and explicit interaction supports teaching the use of freedom and the accompanying responsibility. Missing is the support for creativity, and creative problem solving. However, too much technology might be (depending on the user group) limiting with respect to creativity in general.

\section{Conclusions}

We have presented a structured approach on how to transform an existing learning platform into a progressive education support system. The "Dalton Plan" (Parkhurst, 1923 , 2010) has served as an example, as there exists a vast amount of knowledge on one hand on applying this approach in traditional classroom settings (i.e. without e-learning support), and on the other hand on developing software for learning management and support systems. Bridging that gap for the involved communities required not only studying existing empirical findings but also interviewing e-learning experts experienced in supporting self-organization of learners based on the structure of the Dalton Plan. Both approaches allowed us to develop a contextual design and to implement respective software components.

Concept Maps served as tool for structuring and analysing existing findings, as well as means of aggregation when deriving requirements for the interactive support of Dalton Plan instruments. However, in the course of design several challenges needed to be mastered:

- $\quad$ the user interface migrating social media, content, and organizational elements from the Dalton Plan

- $\quad$ establishing facilitator (teacher) support for those not familiar with the Dalton Plan 
- asynchronous interaction during runtime for learning support conform to the Dalton Plan

- $\quad$ change in feedback culture due to the Dalton Plan concept

The empirical results encourage embodying further progressive education approaches in this way, as the accuracy of mapping the Dalton Plan to e-learning features could be demonstrated. In particular, the consulted experts could recognize the potential of the approach in terms of both structuring knowledge acquisition and supporting selforganization of learning processes. The learners need some introduction to get used to that kind of support once they have been socialized in traditional educational settings. The teachers need to rethink the way they prepare their class, even when studying the meta-assignment or following the structure provided by the Dalton Plan. They need to get used to negotiate individual learning steps, in order to enable students achieving the commonly agreed learning objectives. The sample size in the empirical validation through the semi-structured interviews has been small and is a limitation of this study. There seems to be limited interest to adapt existing e-learning systems to didactic approaches stemming from reformist pedagogy. Hence, further empirical tests with the developed features could attract teachers in further exploring the potential of the approach.

With respect to next steps, features seem to become common design and implementation entities (Stary et al., 2015) referring to micro-services that support the composition of complex systems. Federating systems (Weichhart \& Stary, 2014; Wachholder \& Stary, 2015) allows resolving structural and behavioural dependencies at runtime. Both set the stage for future research when integrating pedagogic approaches into learning support systems.

\section{References}

Anderson, L. W., Krathwohl, D. R., Airasian, P. W., Cruikshank, K. A., Mayer, R. E., Pintrich, P. R., \& Wittrock, M. C. (2001). A taxonomy for learning, teaching, and assessing: A revision of Bloom's taxonomy of educational objectives. New York, NY: Longman.

Auinger, A., \& Stary, C. (2005). Didaktikgeleiteter wissenstransfer - Interaktive informationsräume für lern-gemeinschaften im Web. Deutscher Universitäts-Verlag /GWV Fachverlage GmbH, Wiesbaden.

Baxter, G., \& Sommerville, I. (2011). Socio-technical systems: From design methods to systems engineering. Interacting with Computers, 23(1), 4-17.

Bloom, B., Engelhart, M., Furst, E., Hill, W., \& Krathwohl, D. (1956). Taxonomy of educational objectives: The classification of educational goals. Handbook I: Cognitive domain. New York, NY: Longman.

Bogner, A., \& Menz, W. (2002). Das theoriegenerierende Experteninterview Erkenntnisinteresse, Wissensformen, Interaktion. In A. Bogner, B. Litting, \& W. Menz (Eds.), Das Experteninterview - Theorie, Methode, Anwendung (pp. 33-70). Opladen: Leske + Budrich.

Bortz, J., \& Döring, N. (2002). Forschungsmethoden und evaluation: Für human- und sozialwissenschaftler (Vol. 3). Berlin, Heidelberg: Springer-Verlag.

Cañas, A. J., Carff, R., Hill, G., Carvalho, M., Arguedas, M., Eskridge, T. C., ... Carvajal, R. (2005). Concept maps: Integrating knowledge and information visualization. Lecture Notes in Computer Science, 3426, 205-219.

Casanova, D., Moreira, A., \& Costa, N. (2011). Technology enhanced learning in higher 
education: Results from the design of a quality evaluation framework. Procedia Social and Behavioral Sciences, 29, 893-902.

Chiu, P. H. P., \& Li, R. K. Y. (2016). Enhancing student motivation using LectureTools: A cloud-based teaching and learning platform. Knowledge Management \& ELearning, 7(2), 250-264.

Cohen, D. K. (1988). Educational technology and school organization. In R. S. Nickerson \& P. P. Zodhiates (Eds.), Technology in Education: Looking Toward 2020 (pp. 231264). Hillsdale, NJ: Lawrence Erlbaum.

Davis, E. J., Smith, T. J., \& Leflore, D. (2008). Chaos in the classroom - A new theory of teaching and learning. Durham, NC: Carolina Academic Press.

De Jong, T., Weinberger, A., Girault, I., Kluge, A., Lazonder, A. W., Pedaste, M., ... Zacharia, Z. C. (2012). Using scenarios to design complex technology-enhanced learning environments. Educational Technology Research and Development, 60(5), 883-901.

Edwards, J. (1991). To teach responsibility, bring back the Dalton Plan. Phi Delta Kappan, 72(5), 398-401.

Eichelberger, H. (Ed.). (2002). Eine Einführung in die Daltonplan-Pädagogik. Innsbruck, Austria: Studien Verlag.

Eichelberger, H., Laner, C., Kohlberg, W. D., Stary, E., \& Stary, C. (2008). Reformpädagogik goes eLearning: Neue Wege zur Selbstbestimmung von virtuellem Wissenstransfer und individualisiertem Wissenserwerb. München, Wien: Oldenbourg Verlag.

Friedman, R. S., \& Deek, F. P. (2003). Innovation and education in the digital age: Reconciling the roles of pedagogy, technology, and the business of learning. IEEE Transactions on Engineering Management, 50(4), 403-412.

Hackl, D. (2002). Schulentwicklung am beispiel einer grundschulklasse. In $\mathrm{H}$. Eichelberger (Ed.), Eine Einführung in die Daltonplan-Pädagogik (pp. 111-160). Innsbruck, Austria: Studien Verlag.

Helm, C. (2014). COoperative open learning in commercial education: Multilevel analysis of grade 9 students' learning outcomes in accountancy. Reflecting Education, 9(2), 63-84.

Iacob, M. E., Jonkers, H., Lankhorst, M. M., Proper, H., \& Quartel, D. (2012). ArchiMate 2.0 specification: The open group. Van Haren Publishing.

Imran, A. S., Cheikh, F. A., \& Kowalski, S. J. (2016). Automatic annotation of lecture videos for multimedia driven pedagogical platforms. Knowledge Management \& ELearning, 8(4), 550-580.

Islam, S., \& Omasreiter, H. (2005). Systematic use case interviews for specification of automotive systems. In Proceedings of the 12th Asia-Pacific Software Engineering Conference (pp. 17-24). Taipei, Taiwan.

Kandiko, C. B., \& Kinchin, I. M. (2012a). Challenges in cross-cultural PhD supervision: Mapping to facilitate dialogue. In Proceedings of the Fifth International Conference on Concept Mapping (pp. 57-64). Msida, Malta.

Kandiko, C. B., \& Kinchin, I. M. (2012b). Follow the arrows: Tracing the underlying structure of a doctorate. In Proceedings of the Fifth International Conference on Concept Mapping (pp. 236-243). Msida, Malta.

Konrad, K., \& Traub, S. (1999). Selbstgesteuertes lernen in theorie und praxis. München: Oldenbourg Schulbuchverlag.

Krathwohl, D. R. (2002). A revision of Bloom's taxonomy: An overview. Theory into Practice, 41(4), 212-218.

Lee, L. F. (2000). The Dalton Plan and the loyal, capable intelligent citizen. History of Education 29(2), 129-138.

Lemieux, C. M. (2001). Learning contracts in the classroom: Tools for empowerment and 
accountability. Social Work Education, 20(2), 263-276.

Li, T. M. H., Chau, M., Sung, W., Lee, A. J., Wong, P. W. C., \& Yip, P. S. F. (2016). Design and evaluation of a facebook game for self-directed learning. Knowledge Management \& E-Learning, 8(3), 464-480.

Lillard, A. S. (2007). Montessori: The science behind the genius (2nd ed.). New York, NY: Oxford University Press.

Lindgaard, G., Dillon, R., Trbovich, P., White, R., Fernandes, G., Lundahl, S., \& Pinnamaneni, A. (2006). User needs analysis and requirements engineering: Theory and practice. Interacting with Computers, 18(1), 47-70.

Lundgren, U. P. (2014). The pedagogy of Hilda Taba and the progressive movement in education. In A. Nordin \& D. Sundberg (Eds.), Transnational Policy Flows in European Education: The Making and Governing of Knowledge in the Education Policy Field (pp. 33-47). Oxford: Symposium Books.

MacDonald, C. J., \& Thompson, T. L. (2005). Structure, content, delivery, service, and outcomes: Quality e-learning in higher education. The International Review of Research in Open and Distance Learning, 6(2): 4.

Mayring, P. (2002). Einführung in die qualitative sozialforschung. Weinheim, Basel: Beltz Studium.

Meuser, M., \& Nagel, U. (2002). ExpertInneninterviews - vielfach erprobt, wenig bedacht - Ein Beitrag zur qualitativen Methodendiskussion. In A. Bogner, B. Litting, \& W. Menz (Eds.), Das Experteninterview - Theorie, Methode, Anwendung (pp. 7193). Opladen: Leske + Budrich.

Mödritscher, F., Garcia-Barrios, V. M., \& Gütl, C. (2004). The past, the present and the future of adaptive e-learning: An approach within the scope of the research project AdeLE. In Proceedings of the International Conference on Interactive Computer Aided Learning (ICL2004). Villach, Austria.

Mooij, T. (2009). Education and ICT-based self-regulation in learning: Theory, design and implementation. Education and Information Technologies, 14(1), 3-27.

Nebe, K., \& Zimmermann, D. (2007). Aspects of integrating user centered design into software engineering processes. Lecture Notes in Computer Science, 4550, 194-203.

Neuhauser, G., \& Wittwer, H. (2002). Das COOL*-Projekt - Der Daltonplan in der Sekundarstufe II - Ein Dalton-inspirierter Schulentwicklungsprozess an der BHAK/BHAS-Steyr. In H. Eichelberger (Ed.), Eine Einführung in die DaltonplanPädagogik (pp. 161-203). Innsbruck, Austria: StudienVerlag.

Neuhauser, G., \& Wittwer, H. (2008). Cooperatives offenes lernen - Neue ansätze einer kollegialen lehrer / -innenfortbildung. In P. H. Wien (Ed.), Lehrer/-innenbildung in Europa (pp. 41-46). Wien-Berlin, LIT-Verlag.

Novak, J. D., \& Cañas, A. J. (2008). The theory underlying concept maps and how to construct and use them (Tech. Rep.). Pensacola: IHMC Florida Institute for Human and Machine Cognition.

Pange, A., \& Pange, J. (2011). Is e-learning based on learning theories? A literature review. World Academy of Science, Engineering \& Technology, 80, 62-66.

Pankowska, M. (2012, June). User participation in information system development. In Proceedings of the International Conference on Information Society (i-Society) (pp. 396-401).

Parkhurst, H. (1923, 2010). Education on the Dalton Plan. Nabu Press.

Pfadenhauer, M. (2002). Auf gleicher Augenhöhe reden. In A. Bogner, B. Litting, \& W. Menz (Eds.), Das Experteninterview - Theorie, Methode, Anwendung (pp. 113-130). Opladen: Leske + Budrich.

Popp, S. (2002). Zwischen Wahrheit und Legende. Zur Verbreitungsgeschichte des Daltonplans. In H. Eichelberger (Ed.), Eine Einführung in die Daltonplan-Pädagogik 
(pp. 33-58). Innsbruck, Austria: StudienVerlag.

Semel, S. F. (1992). The Dalton school: The transformation of a progressive school. New York, NY: Peter Lang Publishing.

Shrock, S. A. (1995). A brief history of instructional development. In G. J. Anglin (Ed.), Instructional Technology: Past, Present, and Future (pp. 11-19). Englewood, CO: Libraries Unlimited.

Skiera, E. (2003). Reformpädagogik in Geschichte und Gegenwart: Eine kritische Einführung. München, Wien: R. Oldenbourg Verlag.

Sorokin, A., \& Elena, S. (2016). Dalton-Plan in the context of reforms of the training process in soviet higher education in 1920-1930s. Anthropologist, 23(1/2), 120-125.

Stary, C. (2007). Intelligibility catchers for self-managed knowledge transfer. In Proceedings of the 7th IEEE International Conference on Advanced Learning Technologies (ICALT) (pp. 517-521).

Stary, C. (2009). The design of e-learning contracts: Intelligibility catchers in praxi. In Proceedings of the 2009 IEEE/WIC/ACM International Joint Conference on Web Intelligence and Intelligent Agent Technology (Vol. 3, pp. 203-206).

Stary, C. (2016). Open organizational learning: Stakeholder knowledge for process development. Knowledge Management \& E-Learning, 8(1), 86-108.

Stary, C., Krenn, F., Lerchner, H., Neubauer, M., Oppl, S., \& Wachholder, D. (2015). Towards stakeholder-centered design of open systems: Learning from organizational learning. In Proceedings of the 32nd European Conference on Cognitive Ergonomics. New York, NY: ACM.

Stary, C., \& Weichhart, G. (2012). An e-learning approach to informed problem solving. Knowledge Management \& E-Learning, 4(2), 195-216.

Tyack, D., \& Tobin, W. (1994). The "grammar" of schooling: Why has it been so hard to change? American Educational Research Journal, 31(3), 453-479.

van der Ploeg, P. (2013). The Dalton Plan: Recycling in the guise of innovation. Paedagogica Historica, 49(3), 314-329.

van der Ploeg, P. (2014). The salient history of Dalton education in the Netherlands. History of Education, 43(3), 368-386.

Wachholder, D., \& Stary, C. (2015). Enabling emergent behavior in systems-of-systems through bigraph-based modeling. In Proceedings of the 6th International Conference on Systems of Systems Engineering (SoSE) (pp. 334-339). IEEE.

Weichhart, G. (2012). Bridging the gap between qualitative, empirical work and software design. In Proceedings of the Fifth International Conference on Concept Mapping. Msida, Malta.

Weichhart, G. (2014). Der Dalton Plan im e-learning: Transformation einer refrompädagogik ins Web. Vol. 152, Schriftenreihe der Johannes-Kepler-Uni Linz, Reihe B. Linz: Trauner Verlag.

Weichhart, G., \& Stary, C. (2014). Traceable pedagogical design rationales for personalized learning technologies: An interoperable system-to-system approach. International Journal of People Oriented Programming, 3(2), 25-55.

Yuan, B. Wang, M., Kushniruk, A.W., \& Peng, J. (2016). Design of a computer-based learning environment to support diagnostic problem solving towards expertise development. Knowledge Management \& E-Learning, 8(4), 540-549.

Zardas, G. (2008). The importance of integrating learning theories and pedagogical principles in AHES (Adaptive Hypermedia Educational Systems). In Proceedings of the 8th IEEE International Conference on Advanced Learning Technologies (ICALT) (pp. 884-885). 